\section{BOOK REVIEW \\ ANATOMY FOR DENTAL \\ MEDICINE, 2ND EDITION

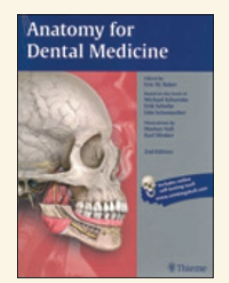

E. W. Baker
Thieme
Price €64.99 pp 576
ISBN
9781626230859

Working in an oral \& maxillofacial unit and being a recent graduate of dental school, my knowledge of head and neck anatomy wasn't as sharp as it should be. This book provided me with a well-presented and illustrated layout of text that informed and consolidated my knowledge of essential surgical anatomy.

Although there are no photos or images of actual cadaveric or surgical prosections, the illustrations are extremely precise, depicting minute detail. The book doesn't just cover anatomy; it addresses histology, developmental, neurological and vascular anatomy. The book also includes illustration and description of anatomy beyond the head and neck including limbs, mediastinum and digestive tract.

The electronic database provides over 1,200 dental anatomy illustrations and self-tests; a crucial element to learning, which those in under/post graduate education will find highly beneficial prior to any examination. The wide array of topics and the adequate level of detail with helpful diagrams make the ownership of this book allencompassing for any undergraduate. It will serve not just as a useful adjunct to study, but as an essential source of information.

This book fuses the topics of many individual books into one. Its precise and appropriate level of detail make for easy reading, making this book suitable for those in either undergraduate or postgraduate education. This book provides a sound and relevant base for understanding, and information that is applicable for practice in university as well as for primary or secondary care practitioners.

B. E. S. DAWOUD

\title{
FROM THE PORTFOLIO
}

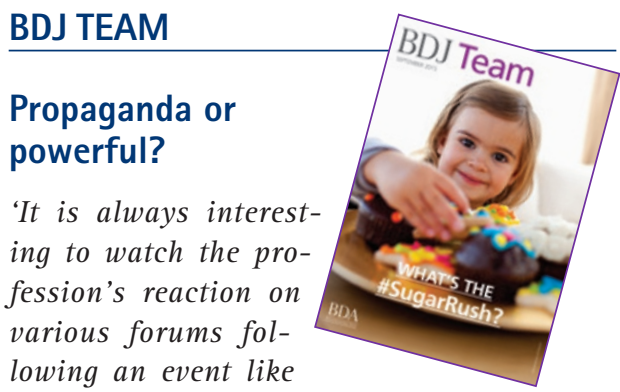

Sugar rush'

It shocked the nation into action, with his petition reaching 100,000 signatures within 48 hours of the documentary airing, but what did we as a profession make of Jamie's Sugar rush? After all, the $B D J$ has been banging on about sugar for 100 years, so what impact could a 60 minute show by a TV chef possibly have? We ask five healthcare professionals for their opinion.

To read more of the September issue of $B D J$ Team go to http://www.nature.com/bdjteam/.

\section{Employment law - are you in the know?}

'There are three types of employment status... the three are often not used correctly in practice and the difference isn't always known'

Sarah Buxton is a dental specialist employment solicitor who acts for dental practice owners, practitioners and managers up and down the country. In September's BDJ Team, Sarah tells us what the three types of employment status are, what their differences are and what employees and employers alike need to know about them.

\section{BDJ STUDENT}

Giving readers the chance to learn 'survival skills' for their future in the profession was the aim of the Autumn issue of BDJ Student. This advice special looked

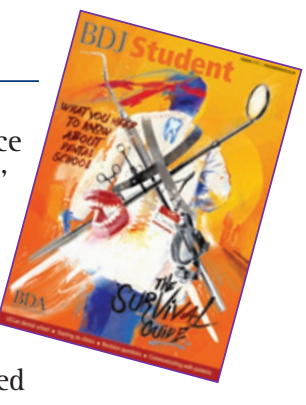
at several different aspects of student and postgraduate life, including how to handle your first time on clinic and communicating with patients.

\section{Starting clinics}

Ajay Mehta, a fourth-year student at King's gave his top tips for the first time a student steps onto clinic. He acknowledged that the experience could be daunting but countered that being prepared was the way to conquer nerves. His advice was:

- Be confident

- Reflect on your mistakes

- Show your personality

- Learn from your tutors

- Be organised
- Get loupes (and a light)

- Get to know your clinical partner.

\section{Communicating with patients}

Patient communication is a skill that students often find difficult to master. With this mind, BDJ Student asked foundation dentist Natalie Bradley to share her experiences of communicating with patients. She advocated using active listening and putting yourself in the patients' shoes as her top strategies to improve communication. She also told readers that it takes times and effort to learn how to communicate with patients but, "the more patients you see the better you will become'.

To read more of the Autumn issue of $B D J$ Student go to https://bdjstudent.co.uk/.

\section{BDJ IN PRACTICE Doubling fine fails Many employers and recruiters are still not assessing someone's right to work in the UK. This is despite the Government doubling} the maximum penalty for those found to be employing illegal workers (from $£ 10,000$ to $£ 20,000$ ).

Readers of the BDJ In Practice October issue are given a tip on how to avoid inadvertently falling foul of the right-to-work rules.

\section{To stop staff behaving badly}

Research by the Institute of Leadership \& Management has revealed the UK's top-ten workplace misdemeanours. The key to putting a stop to them is to have a high-trust, highintegrity working environment, it says.

Number three in the list is badmouthing colleagues. Number two is lying to hide your mistakes. And number one is cutting corners.

To read the full top-ten list and an analysis by ILM Chief Executive Officer Charles Elvin of what the survey results might mean and how businesses can make use of them, go to BDJ In Practice October page 4.

\section{How to spot a fake}

With the Internet rife with counterfeit and substandard dental equipment, readers of BDJ In Practice October are urged on page 13 not to risk their patients' safety or their registration for the sake of a cheap deal.

'The bottom line is to buy from reputable suppliers and know where your product is coming from, writes Executive Director of the British Dental Industry Association, Tony Reed. 